Marquette University

e-Publications@Marquette

College of Nursing Faculty Research and

Publications

Nursing, College of

$1-1-2014$

Efficacy of Achieving Pregnancy with FertilityFocused Intercourse

Qiyan Mu

Marquette University

Richard Fehring

Marquette University, richard.fehring@marquette.edu

Accepted version. MCN: American Journal of Maternal Child Nursing, Vol. 39, No. 1 (January/ February 2014): 35-40. DOI. (C) 2014 Lippincott Williams \& Wilkins, Inc. Used with permission. 


\title{
Efficacy of Achieving Pregnancy with Fertility-Focused Intercourse
}

\author{
Mu, Qiyan BSN, RN \\ College of Nursing, Marquette University \\ Milwaukee, WI \\ Fehring, Richard J. PhD, RN, FAAN \\ College of Nursing, Marquette University \\ Milwaukee, WI
}

\section{Call Out:}

Scientific evidence shows that nearly all pregnancies can be attributed to intercourse during a 6-day period ending on the day of ovulation (the fertile window).

There is a deficit in fertility knowledge and awareness of the fertile window by women of reproductive age seeking pregnancy

The objective of this study was to evaluate the efficacy of focused intercourse on self-estimated high and peak fertile days during the fertile window.

The accuracy of understanding the fertile window and the correct timing of inter-course are crucial to achieve a desired pregnancy.

An online fertility awareness based method is useful in providing fertility knowledge and enhancing the chance of conception for women. 


\begin{abstract}
:
Purpose: To compare pregnancy rates when women have intercourse on selfestimated high and peak fertile days and when they only have intercourse on low fertile days during the fertile window (FW).

Study design and methods: We used a prospective observational cohort study design. Our convenience sample included 124 women who utilized our online charting websites to achieve pregnancy from January 2010 to November 2012. Participants used an electronic hormonal fertility monitor (EHFM) or self-observed cervical mucus or both to determine fertility during the estimated FW. Pregnancy rates were determined with Kaplan-Meier survival analysis. Chi square analysis was used to evaluate the efficacy of achieving pregnancy between two different intercourse patterns.
\end{abstract}

Results: The pregnancy rate was 87 per 100 women at 12 months when intercourse happened on high or peak days and 5 per 100 when intercourse occurred only on low days of the FW. Chi square analysis showed a greater proportion of pregnancies with intercourse on high and peak fertile days of the menstrual cycle $\left(x^{2}=40.2, p<.001, \mathrm{df}=1\right)$.

Implication: Focusing intercourse on high or peak fertile days during the estimated FW enhances the probability of achieving a desired pregnancy. Fertility awareness based online charting system is effective in assisting women determine their fertile window and target intercourse accordingly to achieve pregnancy.

Keywords: fertility awareness, fertile window, intercourse, pregnancy.

Every year, many women contemplate pregnancy. Studies indicated that women are interested in understanding their chances of conceiving and will attempt to utilize their fertility knowledge to help achieve pregnancy (Hammarberg, et al., 2012; Zinaman, Johnson, Ellis, \& Ledger, 2012). These women often actively seek relevant fertility information from media, books and magazines, and the Internet is the number one source of information (Hammarberg, et al., 2012; Kahlor \& Mackert, 2009; Weissman, Gotlieb, Ward, Greenblatt, \& Casper, 2000). The increased availability of Internet access allows more women to search for fertility information online. The degree of anonymity that the Internet provides also contributes to its popularity within the field of reproductive medicine (Malik \& Coulson, 2008). 
Since the Internet facilitates ease of access to valuable fertility resources, it could be an empowering source for women wishing to achieve pregnancy.

However, studies have shown there is a deficit in fertility knowledge and awareness of the fertile window phase of the menstrual cycle by women of reproductive age (Small, Manatunga, \& Marcus 2007; Witt, McEvers, \& Kelly, 2013; Zinaman, Johnson, Ellis, \& Ledger, 2012). Most women are not accurate in estimating their cycle length and FW and may fail to conceive due to mistiming of intercourse (Robinson \& Ellis, 2007; Zinaman et al., 2012). There is a compelling need to educate women about their fertility awareness and primary care providers need to integrate fertility health literacy into health promotion for all women of reproductive age (Barron, 2013).

Scientific evidence shows that nearly all pregnancies can be attributed to intercourse during a 6-day period ending on the day of ovulation for healthy women; these six days are known as the fertile window (FW) (Wilcox, Dunson, \& Baird, 2000; Wilcox, Weinberg, \& Baird, 1995). Several studies have demonstrated that focused intercourse during the FW is associated with shortened conception time (Hilgers, 1992; Gnoth, Godehartdt, Godehartdt, Frank-Herrmann, \& Freundl, 2003; Robinson, Wakelin, \& Ellis, 2007). These studies evaluated the importance of timed intercourse in relation with the FW. Nevertheless, there are levels of fertility (low, high, and peak) within the FW; the two most fertile days are the days before the day of ovulation (Dunson, Baird, Wilcox, \& Weinberg, 1999). No study has attempted to evaluate the pregnancy rates when couples have intercourse on the self-estimated high and peak fertile days compared to having intercourse on the low fertile days within the self-estimated fertile window. So far, there is no clear recommendation regarding fertility-focused intercourse to achieve pregnancy.

In summary, all of the above are important issues that impact women wishing to achieve pregnancy. Yet, we do not know whether focusing intercourse with different levels of fertility is more efficient in helping women achieve pregnancy. The current standard for practice is to recommend that women wishing to achieve pregnancy have frequent random intercourse (American Society for Reproductive Medicine, 2008). This recommendation does not have a strong 
NOT THE PUBLISHED VERSION; this is the author's final, peer-reviewed manuscript. The published version may be accessed by following the link in the citation at the bottom of the page.

evidence base. Therefore, the purpose of our study was to determine and compare pregnancy rates when women have intercourse on selfestimated high and peak fertile days during the fertile window and when they only have intercourse on low self-estimated fertile days during the fertile window. We hypothesized that there will be a higher pregnancy rate and higher proportion of pregnancies when women have intercourse on self-estimated high and peak fertile days during the fertile window compared when they do not have intercourse on those days.

\section{Methods}

\section{Design, Participants, and Procedure}

We used a 12-month prospective observational cohort design to study women seeking pregnancy with the use of a natural family planning (NFP) method provided by our nurse-managed online education and support system. A priori power analysis based on an alpha level of .05, moderate effect size, and 1-beta power of .90 yielded a minimal sample size of 117 . Our final sample included 124 women who enrolled in our web site and charting system from January 2010 through November 2012. The women applied either cervical mucus monitoring (CMM) or electronic hormonal fertility monitoring (EHFM), or both to estimate their fertility. The online charting helped the woman keep track of her menstrual cycle and predicted her following month's FW with a built-in algorithm. The women were informed that to achieve a pregnancy they should have intercourse on high and peak days based on the fertility monitor and/or cervical mucus ratings. Availability of the Web site was promoted through a variety of online means, such as an NFP online discussion forum for health professionals, fertility blogs, and social websites. Women who wished to use online fertility awareness based method to achieve or avoid pregnancy, or for fertility knowledge were eligible to join the website. Women participants were asked to sign an online consent prior to the access of the website. Our study was approved through the university office of research compliance. The online web site is encrypted through a server system and is accessed only through protected passwords. Only the participants, the professional nurse NFP practitioners, and the designated graduate research assistants could have access to the personal information and fertility charts. 
NOT THE PUBLISHED VERSION; this is the author's final, peer-reviewed manuscript. The published version may be accessed by following the link in the citation at the bottom of the page.

\section{Materials and methods}

The women utilized either an electronic hormonal fertility monitor (EHFM) or self-observed vulvar mucus pattern to estimate the FW in each menstrual cycle. Research suggests that fertile type mucus has a high prediction of conception probability, and self-monitoring of vulvar mucus pattern by the woman is highly effective in identifying the FW (Fehring, 2002; Scarpa et al., 2006). Evidence also indicates that that use of EHFM is effective in predicting the FW and aids women in achieving pregnancy (Robison, Wakelin, \& Ellis, 2007; Tiplady, Jones, Campbell, Johnson, \& Ledger, 2012).

The EHFM used for this study was the Clearblue Easy Fertility Monitor (CBFM), a hand held device that detects a rise in urinary metabolites of estrogen (estrone 3 glucuronide (E3G)) and the threshold of luteinizing hormone (LH) with a test strip. The CBFM was designed for women with cycle lengths between 21 to 42 days. The CBFM provided the user with a low, high and peak reading of fertility. When the monitor detected a significant rise in E3G it provided a high reading and when it detected the $\mathrm{LH}$ threshold a Peak reading (Fehring, 2005). The activated CEFM would also indicate the cycle date, daily fertility status, and whether a test was required for that day. The woman used her first urine in the morning for the testing.

If the woman user chose to use cervical mucus observation to estimate her fertility status she was instructed to observe her cervical mucus on a daily basis and to chart the highest level observed. They were instructed to feel for the sensation of cervical mucus at the vulva throughout the day and especially when voiding and before going to bed. They were also asked to observe any mucus at eye level by lifting it off a tissue and testing it between their fingers. For our study, cervical mucus was self-observed and classified at three levels-low, high, and peak. Observations were based on sensations and appearance of cervical mucus. When no mucus was observed or felt, or mucus that was slightly moist and sticky, minimal, thick, white, and held its shape, was classified as "low" fertile mucus. Mucus that feels wetter, increases in amount becomes thinner, cloudy and slightly stretchy was classified as "high" fertility mucus (this mucus can be considered transitional). Any mucus that the woman participant felt as slippery and was abundant, thin, clear, and stretchy (like egg white) 
was classified as "peak" type mucus. Written, oral, and visual descriptions (pictures) of the three levels of cervical mucus were provided to the CMM users at our website.

\section{Data Collection}

When the participants registered on the online NFP site, they were automatically prompted to complete an online demographic profile. All of the online fertility charts produced by the women participants were observed and recorded from their first cycle of charting until they either achieved pregnancy or stopped charting. Graduate research assistants entered information from the fertility charts and the demographic profile into a SPSS program data file. All pregnancies were confirmed by a home urine test or a physical exam by a physician. The online system also sent a pregnancy evaluation form to the participants to complete. Two NFP professional nurses reviewed all menstrual cycles charted, the pregnancy cycle and the pregnancy evaluation form in order to classify the pregnancy according to intercourse pattern.

\section{Data Analysis}

We used IBM SPSS Version 20 to enter and perform data analysis. Descriptive statistics were used to reflect the demographic characteristics of the women. In order to test our hypothesis we used an approach to analyze pregnancy rates for family planning methods developed by Lamprecht and Trussell (1997) in which pregnancy rates are determine for correct use by including only menstrual cycles in which the user followed the rules of the method in the analysis, pregnancy rates for incorrect use or inconsistent use include only menstrual cycles with incorrect or inconsistent use in the analysis, and total pregnancy rates by including all menstrual cycles in the analysis. Correct use for our study meant that the woman participant had intercourse on high and peak self-oberved fertile days and incorrect use when she did not have intercourse on those days. All pregnancies were confirmed by an online pregnancy evaluation and classified by professional nurse experts in fertility awareness based methods.

Cumulative pregnancy rates were determine by use of Kaplan-Meier survival analysis for correct use pregnancy rates per 100 women over 
12 months of use, for incorrect use over 12 months of use, and for total pregnancy rates per 100 women over 12 months of use. We also conducted a secondary survival analysis to see if there were differences in pregnancy rates between women who were 30 years old or younger compared with those who were older than 30 years. Finally, differences in the proportion of pregnancies during menstrual cycles with intercourse on self-estimated high and peak fertile days was compared with pregnancies during low fertile days of the charted menstrual cycle with Chi square analysis, with a probability of .05 or less.

\section{Results}

\section{Demographics of Study Participants}

The 124 participants were similar in most of the demographics: $86 \%$ white, $95 \%$ married, and $92 \%$ were Catholic. The mean age of the participants was 29.5 years $(S D=4.8$; range $20-42)$ and the mean months of attempting pregnancy was 3.8 months $(S D=6.1$; range 1-38 months). Seventy-six percent of the participants reported they had regular menstrual cycles (within 25-35 days) at the time of registration (Table 1 ). Twenty-five women (20\%) were attempting to become pregnant prior to the use of the online charting and support system. Fourteen women (11\%) were trying for 6 months or more, and 10 women ( $8 \%$ ) were trying for 12 months or more, prior to use of the online charting system. Eight out of the 25 women (32\%) got pregnant with the online charting system within four months of focusing intercourse on the self-estimated high and peakdays during the fertile window.

\section{Cumulative Pregnancy Rates}

The 124 participants recorded a total of 469 cycles while attempting pregnancy. There was at least one focused intercourse on the high or peak day in the estimated fertile window in 259 cycles (see figure 1), and the other 210 cycles had intercourse only on the low days during the estimated fertile window or outside the fertile window. A total of 59 confirmed pregnancies occurred in all the charted cycles. Fifty-seven of those confirmed pregnancy occurred in the 259 cycles where intercourse happened on either high or peak days, and 2 
pregnancies occurred when intercourse happened on the low days during the fertile window.

The total pregnancy rate based on all (correct and incorrect) menstrual cycles was 65 pregnancies per 100 women over 12 months of use. However, Our Kaplan-Meier survival analysis showed a correct use pregnancy rate of 87 per 100 women at 12 months of trying when intercourse happened on either high or peak days during the fertile window, and a pregnancy rate of 5 per 100 women when intercourse happened only on low days during the fertile window (See Table 2 for pregnancy rates by months of use). Of interest, the correct use pregnancy rate for women participants younger than 30 years $(N=71)$ was 100 per 100 women at 12 months of use and 84 for women participants $(\mathrm{N}=53)$ older than 30 years.

Our Chi square analysis demonstrated a statistically higher proportion of pregnancies when couples had intercourse on high and peak days during the FW of compared to when they only had intercourse on low estimated fertile days during the FW $\left(x^{2}=40.2\right.$, $p<.001, \mathrm{df}=1$ ).

\section{Clinical Implications}

The ability to self-estimate the FW of the menstrual cycle and to time intercourse during this window is crucial for women wishing to achieve a desired pregnancy. Our findings were consistent with previous studies that involved focusing intercourse during the selfestimated fertile window with the use of natural indicators of fertility (Hilgers, Daly, Prebil, \& Hilgers, 1992; Gnoth et al., 2003; Robinson \& Ellis, 2007). All these studies highlighted the importance of focused intercourse within the fertile window. Furthermore, our study provided evidence that timed intercourse during self-estimated high and peak fertile days in the fertile window produced a significantly higher proportion of pregnancies than when the women did not have intercourse during these optimal fertile days.

Currently the only guideline regarding intercourse patterns to assist women to achieve pregnancy is to have frequent intercourse, i.e., optimally every other day (American Society for Reproductive Medicine, 2008). This guideline is not evidence-based other than the 
belief that frequent intercourse should result in some acts in the FW and that optimal sperm concentrations occur with every other day intercourse. Our study provides strong evidence to support that intercourse in correlation with high and peak fertile days can optimize the women's chance of conception. This offers scientific evidence to support a more concrete recommendation regarding intercourse pattern in relationship with FW to achieve pregnancy. Advance nurse practitioners working with women should incorporate this knowledge into their preconception education (Barron, 2013).

Fertility awareness is a key factor in helping women to achieve pregnancy. Our online charting system provided self-learning information for women to increase their fertility awareness. There was also a forum during which women could ask questions regarding their fertility. Two NFP professional nurses provided consults and answers for women. Our fertility knowledge education was delivered over the internet and women could access this information anywhere and anytime. This has many advantages compared to the traditional inperson fertility teaching. Online fertility education offers more economical and convenient approach to fertility education on a large scale. Internet-based intervention allows more individualization and flexibility for the participants. Our study suggests the combination of professional nurses and online fertility charting system is advantageous to educate women about their fertility.

Our online fertility awareness based charting system also demonstrates the potential to be utilized as an evaluation tool for women's fertility. Currently, most women are encouraged to have regular and unprotected intercourse for at least one year before further fertility evaluation. Our data shows that $35(61 \%)$ of the women achieved pregnancy within first month, and the majority of the pregnancy (98\%) occurred within six months of focused intercourse on high and peak fertility days. The pregnancy rate declines reversely as time goes on. This indicates that for women with normal fertility, timed intercourse usually leads to successful pregnancy within six months (Gnoth et al., 2003). We recommend that fertility charting and targeted intercourse with high and peak fertility should be utilized as the first line of fertility evaluation and intervention to help women to achieve pregnancy. 
Our findings are limited by our small and convenient sampling. Nevertheless, there is clear evidence that an online fertility awarenessbased method can assist women to learn about fertility knowledge and determine their fertile window to optimize their opportunity of achieving a desired pregnancy. We recommend that healthcare providers, who work with women trying to achieve pregnancy, evaluate the women's fertility awareness and understanding of the FW. Based on the widely available Internet, the healthcare provider should incorporate relevant and credible online fertility resources into patient education, and guide women in using these online resources correctly.

\section{References}

1. American Society for Reproductive Medicine. (2008). Optimizing natural fertility. Fertility and Sterility, 90(S3), S1-6, doi:

10.1016/j.fertnstert.2008.08.122

2. Barron, M. L. (2013). Fertility Literacy for women in primary care settings. The Journal for Nurse Practitioner, 9(3), 161-165. doi:10.1016/j.nurpra.2012.11.001

3. Dunson, D. B., Baird, D. D., Wilcox, A. J., \& Weinberg, C. R. (1999). Dayspecific probabilities of clinical pregnancy based on two studies with imperfect measures of ovulation. Human Reproduction, 14(7), 18351839. doi: $10.1093 /$ humrep/14.71835

4. EMD Serono. (2011). In the know: Fertility IQ 2011 survey. Retrieved from http://www.npr.org/assets/news/2011/11/FertilityWhitePaper_Final.pd $f$

5. Fehring, R. (2005). New low- and high-tech calendar methods of family planning. Journal of Midwifery and Women's Health, 50(1), 31-38. doi: 10.1016/j.jmwh.2004.07.001

6. Fehring, R. (2002). Accuracy of the peak day of cervical mucus as a biological marker of fertility. Contraception, 66(4), 231-235. doi: 10.1016/S0010-7824 (02) 00355-4

7. Gnoth, C., Godehardt, D., Godehardt, E., Frank-Herrmann, P., \& Freundl, G. (2003). Time to pregnancy: Results of the German prospective 
NOT THE PUBLISHED VERSION; this is the author's final, peer-reviewed manuscript. The published version may be accessed by following the link in the citation at the bottom of the page.

study and impact on the management of infertility. Human Reproduction, 18(9), 1959-1966. doi: 10.1093/humrep/deg366

8. Hammarberg, K., Setter, T., Norman, R.J., Holden C.A., Michelmore, J., and Johnson, L. (2012). Knowledge about factors that influence fertility among Australians of reproductive age: a population-based survey. Fertility and Sterility, 99(2), 502-507. doi:

10.1016/j.fertnstert.2012.10.031

9. Hilgers, T. W., Daly, K. D., Prebil, A. M., \& Hilgers, S. K. (1992).

Cumulative pregnancy rates in patients with apparently normal fertility and fertility-focused intercourse. Journal of Reproductive Medicine, 37(10), 864-866.

10. Kahlor, L. A., \& Mackert, M. (2009). Perception of infertility information and support sources among female patients who access the Internet. Fertility and Sterility, 91(1), 83-90. doi:

10.1016/j.fertnstert.2007.11.005

11. Lamprecht, V., \& Trussell, J. (1997). Effectiveness studies on natural methods of natural family planning. Advances in Contraception, $13(2 / 3), 155-65$.

12. Malik, S. H., \& Coulson, N. S. (2008). The male experience of infertility: A thematic analysis of an online infertility support group bulletin board. Journal of Reproductive and Infant Psychology, 26(1), 18-30. doi: $10.1080 / 02646830701759777$

13. Robinson, J. E., Wakelin, M., \& Ellis, J. E. (2007). Increased pregnancy rate with use of the Clearblue Easy Fertility Monitor. Fertility and Sterility, 87(2), 329-334. doi: 10.1016/j.fertnstert.2006.05.054

14. Robinson, J. E., \& Ellis, J. E. (2007). Mistiming of intercourse as a primary cause of failure to conceive: Result of a survey on use of a home-use fertility monitor. Current Medical Research and Opinion, 23(2), 301-306. doi: 10.1185/030079906X162863

15. Scarpa, B., Dunson, D. B., \& Colombo, B. (2006). Cervical mucus secretions on the day of intercourse: An accurate marker of highly fertile days. European Journal of Obstetrics \& Gynecology and

MCN, The American Journal of Maternal/Child Nursing, Vol. 39, No. 1 (January/February 2014): pg. 35-40. DOI. This article is (C) Lippincott Williams \& Wilkins, Inc. and permission has been granted for this version to appear in ePublications@Marquette. Lippincott Williams \& Wilkins, Inc. does not grant permission for this article to be further copied/distributed or hosted elsewhere without the express permission from Lippincott Williams \& Wilkins, Inc. 
NOT THE PUBLISHED VERSION; this is the author's final, peer-reviewed manuscript. The published version may be accessed by following the link in the citation at the bottom of the page.

Reproductive Biology, 125(1), 72-78. doi:

10.1016/j.ejogrb.2005.07.024

16. Small, C. M., Manatunga, A. K., \& Marcus, M. (2007). Validity of selfreported cycle length. Annals of Epidemiology, 17(3), 163-170. doi: 10.1016/j.annepidem.2006.05.005

17. Tiplady, S. Jones, G., Campbell, M., Johnson, S., \& Ledger, W. (2012). Home ovulation tests and stress in women trying to conceive: $A$ randomized controlled trail. Human Reproduction, 28(1), 138-151. doi: 10.1093/humrep/des372

18. Weissman, A., Gotlieb, L., Ward, S., Greenblatt, E., \& Casper, R. F. (2000). Use of the Internet by infertile couples. Fertility and sterility, 73(6), 1179-1182. doi: 10.1016/Soo15-0282 (00) 00515-X

19. Wilcox, A. J., Weinberg, C. R., \& Baird, D. D. (1995). Timing of sexual intercourse in relation to ovulation: Effects on the probability of conception, survival of the pregnancy, and sex of the baby. The New England Journal of Medicine, 333(23), 1517-1521. doi: 10.1056/NEJM199512073332301

20. Wilcox, A. J., Dunson, D., \& Baird, D. D. (2000). The timing of the "fertile window" in the menstrual cycle: Day specific estimate from a prospective study. British Medical Journal, 321(7271), 1259-1262. doi: 10.1136/bmj.321.7271.1259

21. Witt, J., McEvers, K., \& Kelly, P. (2013). Knowledge and experiences of low-income patients with natural family planning. The Journal of Nurse Practitioners, 9(2), 99-104. doi: 10.1016/j.nurpra.2012.06.010

22. Zinaman, M., Johnson, S., Ellis, J., \& Ledger, W. (2012). Accuracy of perception of ovulation day in women trying to conceive. Current Medical Research \& Opinion, 28(5), 749-754. doi: 10.1185/03007995.2012.681638

MCN, The American Journal of Maternal/Child Nursing, Vol. 39, No. 1 (January/February 2014): pg. 35-40. DOI. This article is (C) Lippincott Williams \& Wilkins, Inc. and permission has been granted for this version to appear in ePublications@Marquette. Lippincott Williams \& Wilkins, Inc. does not grant permission for this article to be further copied/distributed or hosted elsewhere without the express permission from Lippincott Williams \& Wilkins, Inc.. 
NOT THE PUBLISHED VERSION; this is the author's final, peer-reviewed manuscript. The published version may be accessed by following the link in the citation at the bottom of the page.

\section{About the Authors}

Qiyan Mu : Nursing PhD student and graduate research assistant, Marquette University, Milwaukee, WI.

e-mail : Qiyan.mu@marquette.edu

Richard J. Fehring : Professor Emeritus, Marquette University, Milwaukee, WI.

The authors declare no conflicts of interest.

MCN, The American Journal of Maternal/Child Nursing, Vol. 39, No. 1 (January/February 2014): pg. 35-40. DOI. This article is (c) Lippincott Williams \& Wilkins, Inc. and permission has been granted for this version to appear in e-

Publications@Marquette. Lippincott Williams \& Wilkins, Inc. does not grant permission for this article to be further copied/distributed or hosted elsewhere without the express permission from Lippincott Williams \& Wilkins, Inc.. 
NOT THE PUBLISHED VERSION; this is the author's final, peer-reviewed manuscript. The published version may be accessed by following the link in the citation at the bottom of the page.

Table 1. Demographics of the participants by mean, standard deviation, and range of scores. $(\mathrm{N}=124)$

\begin{tabular}{ll}
\hline Mean attempting months & $3.8(\mathrm{SD} 6.1 ; 1-38)$ \\
Mean age of the women & $29.5(\mathrm{SD} 4.8 ; 20-42)$ \\
Mean years married & $4.3(\mathrm{SD} 5.0 ; 0-19)$ \\
Mean BMI & $24.6(\mathrm{SD} 5.2 ; 17-46)$ \\
\% Reproductive category & $76 \%$ regular $9 \%$ long \\
\% Ethnicity & $86 \%$ Euro-American 3\% Hispanic \\
& American 2\% Native American \\
\% Religion & $92 \%$ Catholic 6\% Protestant/other \\
& Christian \\
& $51 \% 17+$ year 26\% $15-16$ years $14 \%$ \\
& $13-14$ years
\end{tabular}

Figure 1: Pregnancy Cycle with Correct Use Intercourse Pattern on High and Peak Fertility Rated Days

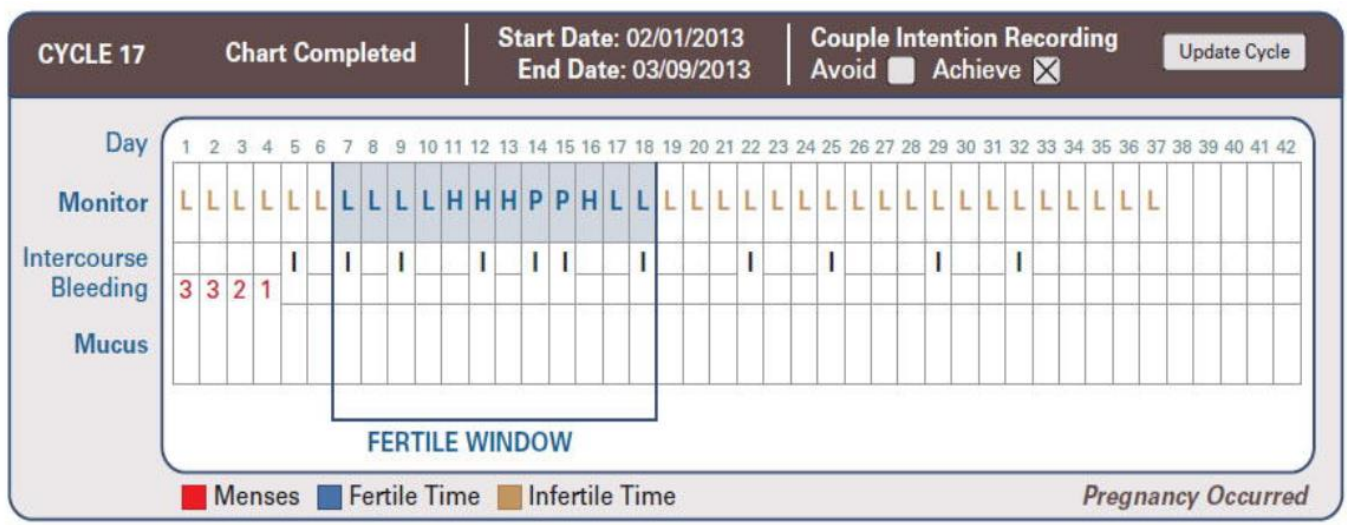

MCN, The American Journal of Maternal/Child Nursing, Vol. 39, No. 1 (January/February 2014): pg. 35-40. DOI. This article is (C) Lippincott Williams \& Wilkins, Inc. and permission has been granted for this version to appear in ePublications@Marquette. Lippincott Williams \& Wilkins, Inc. does not grant permission for this article to be further copied/distributed or hosted elsewhere without the express permission from Lippincott Williams \& Wilkins, Inc.. 
NOT THE PUBLISHED VERSION; this is the author's final, peer-reviewed manuscript. The published version may be accessed by following the link in the citation at the bottom of the page.

Table 2: Pregnancy rates by correct and incorrect use cycles per 100 women over 12 months of use

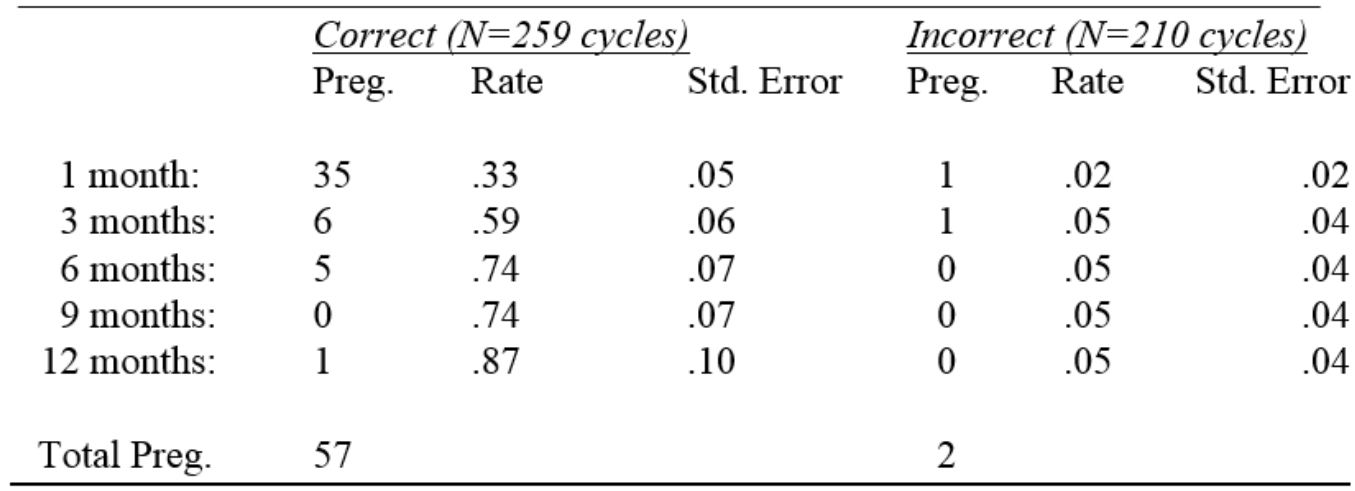

Note: Correct use means that women had intercourse on high or peak fertility days. Incorrect use means that women only had intercourse on low fertility days

\section{Clinical Implications}

- Fertility awareness is crucial for women wish to achieve a desired pregnancy.

- Our study provides strong evidence to support that intercourse in correlation with high and peak fertile days can optimize the women's chance of conception.

- An online fertility awareness based method is an economic and convenient approach to teach fertility awareness on a large scale.

- Health care providers working with women trying to achieve pregnancy should evaluate women' fertility awareness and understanding of the fertile window.

- Health care providers should incorporate relevant and credible online fertility resources into preconception education. 